\title{
Hybrid ionic liquid/water-in-salt electrolytes enable stable cycling of LTO/NMC811 full cells
}

\author{
Maximilian Becker, ${ }^{1,2}$ David Reber, ${ }^{1}$ Abdessalem Aribia, ${ }^{1,2}$ Corsin Battaglia, ${ }^{1}$ Ruben-Simon Kühnel ${ }^{1 *}$ \\ 1) Empa, Swiss Federal Laboratories for Materials Science and Technology, 8600 Dübendorf, \\ Switzerland \\ 2) ETH Zurich, Department of Materials, 8093 Zurich, Switzerland
}

*Email: ruben-simon.kuehnel@empa.ch

\begin{abstract}
Water-in-salt electrolytes have successfully expanded the electrochemical stability window of aqueous electrolytes to up to $3 \mathrm{~V}$. While particularly the reductive stability of water-in-salt electrolytes can be further improved by simply increasing the salt concentration, this approach has its limitations as it leads to very viscous and hence poorly conducting solutions. An alternative strategy is the partial substitution of water by ionic liquids, which boosts the lithium bis(trifluoromethanesulfonyl)imide (LiTFSI) solubility while maintaining adequate transport properties at very high salt concentrations.

Here, we study such ternary electrolytes based on LiTFSI, water, and imidazolium-type ionic liquids in terms of their thermal, electrochemical, and transport properties. We find that the LiTFSI solubility increases from $21 \mathrm{~mol} \mathrm{~kg}^{-1}$ in water to up to $60 \mathrm{~mol} \mathrm{~kg}^{-1}$ in the presence of these ionic liquids. Deconvolution of the different contributions to the LiTFSI solubility shows that particularly the ionic liquid 1-ethyl-3-methylimidazolium trifluoromethanesulfonate acts as solubility enhancer.

The increased reductive stability of these ternary electrolytes enables stable cycling of both $\mathrm{TiO}_{2}$ and $\mathrm{Li}_{4} \mathrm{Ti}_{5} \mathrm{O}_{12}$ anodes. We further show that the low water content of these electrolytes also allows stable cycling of $\mathrm{LiNi}_{0.8} \mathrm{Mn}_{0.1} \mathrm{Co}_{0.1} \mathrm{O}_{2}$ (NMC811) cathodes. For instance, a TiO $/ \mathrm{NMC} \mathrm{N11}$ full cell based on such a hybrid electrolyte shows an energy density of $121 \mathrm{Wh} \mathrm{kg}^{-1}$ on the active material level, a Coulombic efficiency of $>99.7 \%$ at $C / 2$, and retains $80 \%$ of its initial capacity after 290 cycles at this rate. Owing to the $300 \mathrm{mV}$ lower redox potential of $\mathrm{Li}_{4} \mathrm{Ti}_{5} \mathrm{O}_{12}$ compared to $\mathrm{TiO}_{2}, \mathrm{Li}_{4} \mathrm{Ti}_{5} \mathrm{O}_{12} / \mathrm{NMC} 811$ full cells reach energy densities of 141 and $150 \mathrm{Wh} \mathrm{kg}^{-1}$ at a rate of $1 \mathrm{C}$ and C/2, respectively. These cells still show Coulombic efficiency of $99.4 \%$ and $99.2 \%$, respectively, and maintain $80 \%$ of their initial capacity after 230 and 154 cycles, respectively. Considering the large number of potential lithium salt-ionic liquid combinations, we anticipate further improvements in electrolyte properties and subsequently cell performance.
\end{abstract}




\section{Introduction}

State-of-the-art lithium-ion batteries (LIBs) are based on highly flammable organic electrolytes. ${ }^{1,2}$ To improve the intrinsic safety of LIBs, research efforts have focused on replacing flammable organic solvents by non-flammable alternatives. ${ }^{3-5}$ Water as electrolyte solvent is inherently non-flammable, non-toxic, and abundant, but its narrow electrochemical stability window (ESW) of thermodynamically only $1.23 \mathrm{~V}$ at $25^{\circ} \mathrm{C}$ has excluded it from being employed in high-voltage LIBs. In 2015, Suo et al. introduced the concept of water-in-salt (WIS) electrolytes by demonstrating a stable solution of 21 moles of lithium bis(trifluoromethanesulfonyl)imide (LiTFSI) per kilogram of water (here denoted as $21 \mathrm{~m}$ ). ${ }^{6}$ The high salt concentration significantly expands the ESW to $3.0 \mathrm{~V}$ on stainless steel electrodes while maintaining an ionic conductivity of $9.5 \mathrm{mS} \mathrm{cm}^{-1}$ at $25^{\circ} \mathrm{C}$. This value is comparable to the conductivity of carbonate-based organic electrolytes, despite the high salt concentration. The WIS electrolyte approach has enabled the first rechargeable aqueous LIB operating at a relatively high average discharge voltage of $1.75 \mathrm{~V}$ by employing $\mathrm{LiMn}_{2} \mathrm{O}_{4}(\mathrm{LMO})$ as cathode and $\mathrm{Mo}_{6} \mathrm{~S}_{8}$ as anode. ${ }^{6}$

The enhanced electrochemical stability of WIS electrolytes originates from a drastically reduced water content resulting in a peculiar electrolyte structure with anions being incorporated into the primary solvation shell of the Li ions. ${ }^{6}$ With this structure, the electrolyte is also able to form an anion-derived SEI on the anode. ${ }^{7,8}$ Simultaneously, TFSI anions align in the electrochemical double-layer at the cathode/electrolyte interface, establishing a water-depletion zone, resulting in particularly high oxidative stability of $>4.5 \mathrm{~V}$ vs. $\mathrm{Li} / \mathrm{Li}^{+} .9$

However, despite convincing evidence for the formation of an anode SEI in WIS electrolytes, effective suppression of the hydrogen evolution reaction (HER) is limited to potentials above ca. $1.9 \mathrm{~V}$ vs. $\mathrm{Li}^{-\mathrm{Li}^{+} .} 6$ At lower potentials, water molecules increasingly accumulate at the anode/electrolyte interface, facilitating HER and thus preventing the formation of a dense SEI. ${ }^{8}$ Combination of two highly soluble lithium salts enables even higher concentrations such as $28 \mathrm{~m}$, which slightly further extends the ESW of WIS electrolytes, but ultimately does not solve this cathodic challenge. ${ }^{10}$ This limitation has significant consequences as already $\mathrm{Li}_{4} \mathrm{Ti}_{5} \mathrm{O}_{12}$ (LTO), an important anode material for LIBs, cannot be operated in such WIS electrolytes, although its average redox potential shifts to ca. $1.8 \mathrm{~V} \mathrm{vs}$. $\mathrm{Li}^{\mathrm{Li}} \mathrm{Li}^{+}$in WIS electrolytes (Nernst shift due to the high lithium-ion concentration). ${ }^{11}$

As WIS electrolytes are usually saturated solutions at room temperature, they tend to crystallize below room temperature. Some of us recently discovered that certain anions with an asymmetric chemical structure kinetically suppress this crystallization. ${ }^{12}$ The quest for asymmetric anions has led to the introduction of the salt lithium (pentafluoroethanesulfonyl)(trifluoromethanesulfonyl)imide (LiPTFSI) to WIS electrolytes. Due to its extremely high solubility of $>30 \mathrm{~m}$ at $25^{\circ} \mathrm{C}$, LiPTFSI enables both WIS electrolytes that remain thermodynamically in the liquid state below $-10^{\circ} \mathrm{C}^{13}$ and the formulation of an overall 56m-concentrated monohydrate-melt electrolyte $\left(\mathrm{Li}(\mathrm{PTFSI})_{0.6}(\mathrm{TFSI})_{0.4} \cdot 1 \mathrm{H}_{2} \mathrm{O}\right){ }^{14} \quad$ The unprecedentedly high lithium concentration of the latter electrolyte further widens the ESW, enabling the use of LTO anodes. However, this electrolyte suffers from low conductivity of only $0.1 \mathrm{mS} \mathrm{cm}^{-1}$ at $30{ }^{\circ} \mathrm{C}$ related to its high viscosity of $8555 \mathrm{mPa}$ s. Hence, solely rising the lithium salt concentration has 
its limitations and new approaches are needed to tackle the cathodic challenge in aqueous electrolyte research.

As a potential solution, Chen et al. reported a WIS electrolyte where half of the water molecules are substituted by acetonitrile. ${ }^{15}$ This hybrid electrolyte remains non-flammable, shows enhanced electrochemical stability, and can be operated below $0{ }^{\circ} \mathrm{C}$. However, acetonitrile is a volatile organic solvent. Recently, addition of the electrochemically inert organic salt tetraethylammonium trifluoromethanesulfonate to a sodium-based WIS electrolyte has shown to be an effective strategy to further reduce the water content, enabling stable cycling of a $1.74 \mathrm{~V}$ aqueous sodium-ion battery. ${ }^{16}$ Combining large organic cations with large organic anions typically results in salts with low melting points, i.e. ionic liquids (ILs), another class of non-flammable and non-volatile solvents. Here, we define an IL as a salt with a melting point of less than $100^{\circ} \mathrm{C}$. Following this strategy, Chen et al. reported a hybrid electrolyte containing LiTFSI, water, and the IL ethyltrimethylammonium TFSI. ${ }^{17}$ Importantly, with a concentration of $42 \mathrm{~m}$ LiTFSI, a strongly enhanced lithium salt solubility with respect to water was observed upon addition of the $\mathrm{IL} .{ }^{17}$ As a second benefit of the IL, the electrolyte with an overall concentration of $63 \mathrm{~m}(42 \mathrm{~m} \mathrm{LiTFSI}+21 \mathrm{~m} \mathrm{IL})$ shows much better transport properties with a conductivity of $0.9 \mathrm{mS} \mathrm{cm}^{-1}$ at $25^{\circ} \mathrm{C}$ compared to classical WIS electrolytes only containing lithium salts like the 56molal LiPTFSI/LiTFSI electrolyte introduced above. ${ }^{14,17}$

Here, we prepare hybrid electrolytes based on the room temperature ionic liquids (RTILs) 1-ethyl-3methylimidazolium TFSI (EMImTFSI) and EMIm trifluoromethanesulfonate (EMImOTf). We study the effect of addition of these RTILs to LiTFSI/ $\mathrm{H}_{2} \mathrm{O}$ solutions in terms of thermal, electrochemical, and transport properties as well as LiTFSI solubility. We show that the LiTFSI solubility increases from $21 \mathrm{~mol} \mathrm{~kg}^{-1}$ in water to up to $60 \mathrm{~mol} \mathrm{~kg}^{-1}$ in the presence of EMlmOTf. To better understand this behavior, we deconvolute the different contributions to the increased LiTFSI solubility in the presence of these RTILs. Furthermore, we demonstrate that the enhanced LiTFSI concentration results in particularly enhanced reductive stability, translating into good compatibility with $\mathrm{TiO}_{2}$ and LTO anodes. Finally, owing to the reduced water content, these electrolytes also support stable cycling of $\mathrm{LiNi} 0.8 \mathrm{Mn}_{0.1} \mathrm{Co}_{0.1} \mathrm{O}_{2}$ (NMC811) cathodes.

\section{Results and Discussion}

In this study, we employ EMIm-based RTILs due to the typically lower viscosity of imidazoliumcompared to, e.g., quaternary ammonium-based RTILs. ${ }^{18}$ The ability of the TFSI anion to form an SEI and its water-blocking behavior at the cathode/electrolyte interface render TFSI an ideal counter ion for ILS to be added to WIS electrolytes. For comparison, we also included electrolytes based on EMImOTf in this study. In contrast to TFSI, the smaller OTf anion is asymmetric and its higher charge density translates into stronger Coulomb interactions. ${ }^{19}$ Hence, we expect the influence of anion coordination to $\mathrm{Li}^{+}$or water molecules to be more pronounced for OTf compared to TFSI. Additionally, choosing TFSI and OTf allows us to compare a hydrophobic (EMImTFSI) with a completely water-miscible hydrophilic IL (EMImOTf). We note that other cations such as of the quaternary alkyl ammonium type have higher reductive stability than EMIm with its calculated reduction potential of $0.62 \mathrm{~V} \mathrm{vs.} \mathrm{Li/Li+.}{ }^{20}$ However, we do not expect the reductive stability of EMIm to limit the ESW of IL-containing WIS electrolytes as this 
potential is $2 \mathrm{~V}$ more negative than the thermodynamic potential of the hydrogen evolution reaction (HER) at neutral pH (2.6 V vs. Li/Li+). In the following, all molalities for RTIL-containing WIS electrolytes are reported with respect to water (moles of lithium salt/RTIL per kilogram of water).

To study the effect of EMImTFSI and EMImOTf on the LiTFSI solubility in WIS electrolytes, we investigated the thermal behavior of multiple LiTFSI-RTIL-water ternary mixtures via differential scanning calorimetry (DSC). Whereas $20 \mathrm{~m}$ LiTFSI exhibits distinct crystallization and melting events, addition of $20 \mathrm{~m}$ EMImTFSI (sample denoted as 20/20-TFSI with TFSI referring to the anion of the RTIL) results in suppressed crystallization during the cooling scan and a glass transition (Fig. 1a). Interestingly, the liquidus temperature $\left(T_{\mathrm{L}}\right)$ appears to drop from $15{ }^{\circ} \mathrm{C}$ for $20 \mathrm{~m}$ LiTFSI to $-29{ }^{\circ} \mathrm{C}$ for $20 / 20$-TFSI. However, the melting of 20/20-TFSI is hardly visible in the DSC curve due to the suppressed crystallization. Such a low $T_{\mathrm{L}}$ indicates that the solution is not saturated at room temperature, i.e. the LiTFSI and/or EMImTFSI concentration could be increased while retaining a $T_{L}$ below room temperature. Indeed, when fixing the EMImTFSI molality at $20 \mathrm{~m}$, the LiTFSI concentration can be more than doubled to $45 \mathrm{~m}$, while $T_{\mathrm{L}}$ increases to $23^{\circ} \mathrm{C}$. For hydrophilic EMImOTf instead of hydrophobic EMImTFSI, the $T_{\mathrm{L}}$ of the equivalent solution (20/20-OTf) drops to a similar temperature of $-26^{\circ} \mathrm{C}$ (Fig. 1 b) and the LiTFSI concentration can even be raised to more than $50 \mathrm{~m}\left(T_{\mathrm{L}}=11^{\circ} \mathrm{C}\right.$ for $50 / 20$-OTf). By increasing the RTIL content, the LiTFSI solubility at room temperature can be further increased to e.g. at least $55 \mathrm{~m}$ and $60 \mathrm{~m}$ for EMImTFSI and EMImOTf, respectively, for a RTIL molality of $30 \mathrm{~m}$, resulting in electrolytes with overall molalities of $85 \mathrm{~m}$ and $90 \mathrm{~m}$.

a)

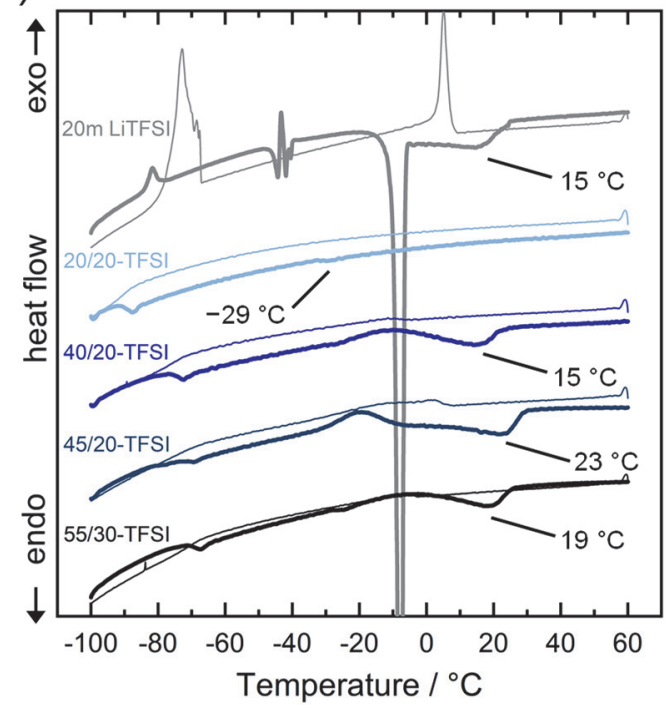

b)

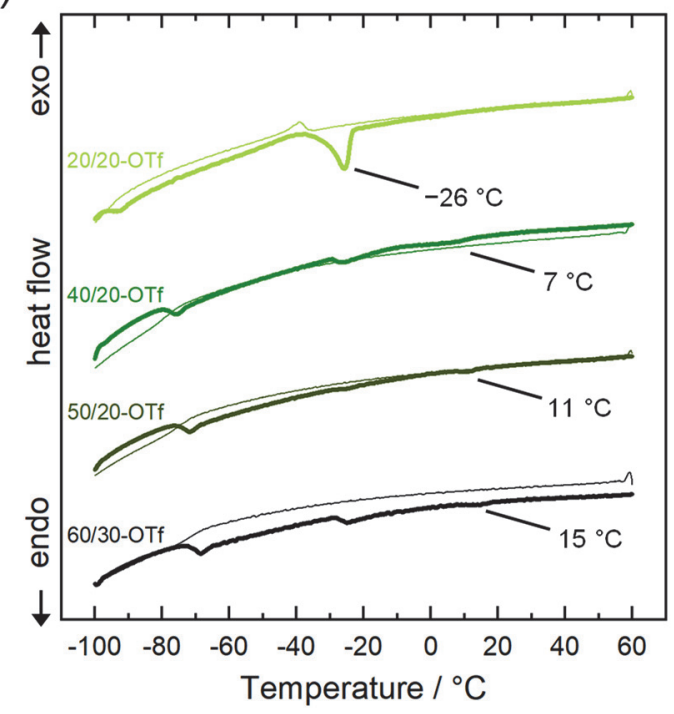

Fig. 1: DSC curves of (a) EMImTFSI-containing aqueous LiTFSI solutions ( $x / y$-TFSI) and (b) EMImOTf-containing aqueous LiTFSI solutions ( $x / y$-OTf) with $x$ being the LiTFSI molality and $y$ being the RTIL molality with respect to water. Prior to cooling, the samples were equilibrated at $60^{\circ} \mathrm{C}$ for $30 \mathrm{~min}$. Cooling (thin line) and heating (thick line) curves were recorded at a scan rate of $1^{\circ} \mathrm{C} \mathrm{min}^{-1}$. Mesocarbon microbeads (MCMBs) were added to each sample to provoke crystallization.

The reduced water content of these electrolytes in terms of their water-to-lithium molar ratio is highlighted in Fig. 2a, which compares this ratio for selected LiTFSI-RTIL-water hybrid electrolytes with that of $21 \mathrm{~m} \mathrm{LiTFSI,} \mathrm{the} \mathrm{archetypical} \mathrm{WIS} \mathrm{electrolyte.} \mathrm{The} \mathrm{number} \mathrm{of} \mathrm{available} \mathrm{water} \mathrm{molecules} \mathrm{per} \mathrm{lithium}$ ion shrinks from 2.65 in $21 \mathrm{~m}$ LiTFSI to 1.39 in a solution containing $40 \mathrm{~m}$ LiTFSI and 20m RTIL (in short: 40/20). Pushing the LiTFSI content to its solubility limit reduces the ratio further to 1.23 for $45 / 20$-TFSI 
and to 1.11 for $50 / 20$-OTf. For $60 / 30$-OTf, the water-to-lithium ratio equals 0.93 . Hence, this solution contains more lithium ions than water molecules. The numbers inside the bars shown in Fig. 2a represent the molar fraction of the different electrolyte components. Except for the 60/30-OTf electrolyte, the molar fraction is highest for water, which is beneficial for transport properties.

The low water fraction of the 60/30-OTf electrolyte manifests itself in a rather low ionic conductivity and high viscosity of $0.4 \mathrm{mS} \mathrm{cm}^{-1}$ and $1125 \mathrm{mPa} \mathrm{s}$ at $25^{\circ} \mathrm{C}$, respectively. Considering the overall molality of this solution of $90 \mathrm{~m}$, these transport properties are still surprisingly good. Temperature-dependent viscosity and conductivity data of selected LiTFSI-EMImTFSI/EMImOTf-water solutions are given in Table 1. For comparison, the table also contains values for $20 \mathrm{~m}$ LiTFSI. Upon addition of RTIL, the conductivity slightly decreases from $10.4 \mathrm{mS} \mathrm{cm}^{-1}$ (20m LiTFSI) to $6.7 \mathrm{mS} \mathrm{cm}^{-1}$ (20/20-TFSI) at $25^{\circ} \mathrm{C}$. Taking into account the doubling of the overall salt concentration, this is only a minor drop. In contrast, the viscosity slightly decreases from $55.3 \mathrm{mPa}$ s for $20 \mathrm{~m} \mathrm{LiTFSI} \mathrm{to} 44.2 \mathrm{mPa}$ s for 20/20-TFSI. We interpret this observation as a kind of plasticizer effect of the RTIL, a phenomenon that is typically observed for polymer electrolytes in which RTILs are used to increase polymer chain mobility. ${ }^{21,22}$ However, increasing the LiTFSI concentration further leads to much lower conductivities of e.g. 2.9 and $1.2 \mathrm{mS} \mathrm{cm}^{-1}$ for 30/20TFSI and 40/20-TFSI, respectively, due to stronger interactions of $\mathrm{Li}^{+}$with water and anions compared to EMIm. We find the same trend for EMImOTf-containing electrolytes, which correlates well with the behavior of binary lithium salt-ionic liquid electrolytes that show decreasing ionic conductivities upon increasing lithium molar fractions. ${ }^{23-25}$ In light of their suitability for battery applications, we selected the following electrolytes with a conductivity of at least $1 \mathrm{mS} \mathrm{cm}^{-1}$ at $25^{\circ} \mathrm{C}$ for the subsequent experiments: 40/20-TFSI (1.2 $\left.\mathrm{mS} \mathrm{cm}^{-1}\right)$ and 40/20-OTf $\left(1.4 \mathrm{mS} \mathrm{cm}^{-1}\right)$.

Table 1: Conductivity and viscosity data of selected electrolytes considered for this study. When only conductivity data is reported, the electrolyte is only metastable at that temperature and crystallization occurred during the viscosity experiment.

\begin{tabular}{|c|c|c|c|c|c|c|c|c|}
\hline Electrolyte & $\mathrm{T} /{ }^{\circ} \mathrm{C}$ & 10 & 20 & 25 & 30 & 40 & 50 & 60 \\
\hline \multirow{2}{*}{ 20m LiTFSI } & $\sigma / \mathrm{mS} \mathrm{cm}^{-1}$ & 6.2 & 8.9 & 10.4 & 12.2 & 16.0 & 20.4 & 25.8 \\
\hline & $\eta / \mathrm{mPa} \mathrm{s}$ & - & 69.2 & 55.3 & 45.4 & 30.9 & 21.8 & 16.2 \\
\hline \multirow{2}{*}{ 20/20-TFSI } & $\sigma / \mathrm{mS} \mathrm{cm}^{-1}$ & 3.7 & 5.6 & 6.7 & 8.0 & 11.0 & 14.5 & 18.3 \\
\hline & $\eta / \mathrm{mPas}$ & 90.3 & 55.0 & 44.2 & 36.0 & 24.9 & 18.2 & 13.8 \\
\hline \multirow{2}{*}{ 20/20-OTf } & $\sigma / \mathrm{mS} \mathrm{cm}^{-1}$ & 3.6 & 5.4 & 6.5 & 7.7 & 10.5 & 13.8 & 17.6 \\
\hline & $\eta / \mathrm{mPa} s$ & 96.6 & 60.2 & 48.9 & 40.2 & 28.0 & 20.4 & 15.3 \\
\hline \multirow{2}{*}{ 40/20-TFSI } & $\sigma / \mathrm{mS} \mathrm{cm}^{-1}$ & 0.49 & 0.93 & 1.2 & 1.6 & 2.5 & 3.8 & 5.3 \\
\hline & $\eta / \mathrm{mPa} s$ & - & 407 & 293 & 216 & 125 & 78.5 & 51.9 \\
\hline \multirow{2}{*}{ 40/20-OTf } & $\sigma / \mathrm{mS} \mathrm{cm}^{-1}$ & 0.56 & 1.0 & 1.4 & 1.7 & 2.7 & 4.0 & 5.6 \\
\hline & $\eta / \mathrm{mPa} s$ & - & 410 & 302 & 227 & 138 & 87.4 & 58.0 \\
\hline \multirow{2}{*}{ 60/30-OTf } & $\sigma / \mathrm{mS} \mathrm{cm}^{-1}$ & 0.14 & 0.30 & 0.42 & 0.57 & 1.0 & 1.6 & 2.4 \\
\hline & $\eta / \mathrm{mPa} s$ & - & - & 1125 & 789 & 418 & 243 & 149 \\
\hline
\end{tabular}


a)

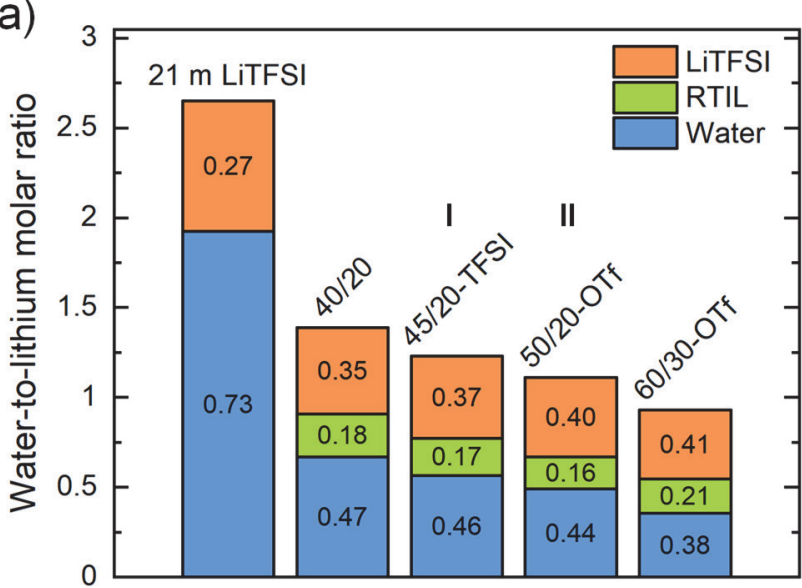

b)

LiTFSI dissolved by

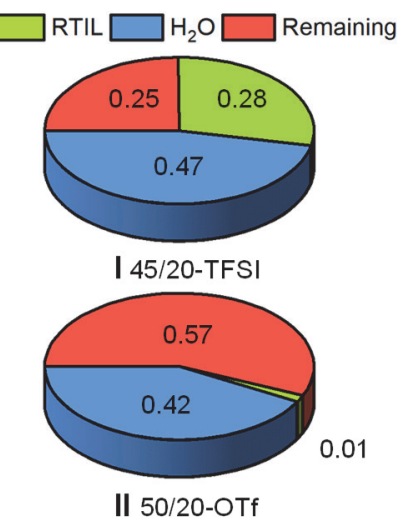

Fig. 2: Increased LiTFSI solubility in RTIL/water mixtures. (a) Water-to-lithium molar ratio for selected electrolytes. Numbers inside the bars represent molar fractions of the respective component. (b) Breakdown of the contributions to the LiTFSI solubility of two selected electrolytes.

To investigate the origin of the enhanced LiTFSI solubility in the presence of the RTILs, we deconvoluted the individual contributions to the LiTFSI solubility by considering the LiTFSI solubility in water and in the RTILs. For EMImTFSI, a LiTFSI solubility of $1.63 \mathrm{~m}$ at $25^{\circ} \mathrm{C}$ was reported, corresponding to a solubility of 12.8 moles of LiTFSI in 20 moles of EMImTFSI. ${ }^{26}$ One kilogram of water dissolves 21 moles of LiTFSI at $23{ }^{\circ} \mathrm{C} .{ }^{27}$ Hence, a solution containing one kilogram of water and 20 moles of EMImTFSI should hypothetically dissolve 33.8 moles of LiTFSI. As a solution containing $20 \mathrm{~m}$ EMImTFSI dissolves up to $45 \mathrm{~m}$ LiTFSI (45/20-TFSI in our notation), the difference of $11.2 \mathrm{~m}$, corresponding to $25 \%$ of the LiTFSI content, remains unexplained by the solubility in the individual solvents. LiTFSI has been reported to have an even lower solubility in EMImOTf of only $0.14 \mathrm{~m}$ at $25^{\circ} \mathrm{C}_{1}{ }^{26}$ corresponding to 0.7 moles of LiTFSI in 20 moles of EMImOTf. Consequently, for sample 50/20-OTf, $28.3 \mathrm{~m} \mathrm{LiTFSI,} \mathrm{corresponding} \mathrm{to} 57 \%$ of the LiTFSI content, cannot be rationalized by the solubility in the individual solvents. Hence, we conclude that these ILs act as solubility enhancer for LiTFSI in water. The calculations are visualized in Fig. $\mathbf{2 b}$.

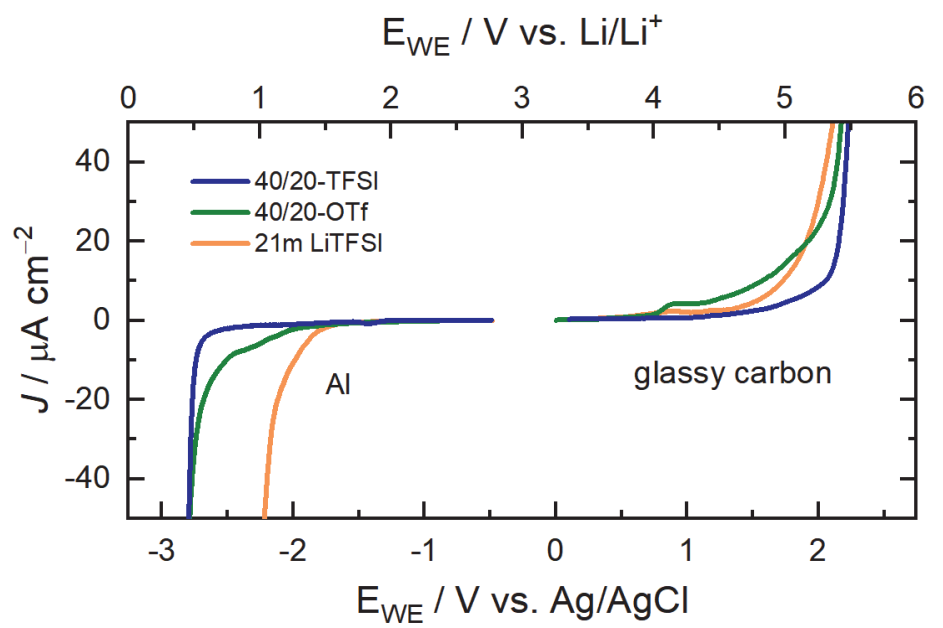

Fig. 3: Voltammograms of selected electrolytes recorded with a scan rate of $1 \mathrm{mV} \mathrm{s}^{-1}$ on Al and glassy carbon working electrodes for cathodic and anodic scans, respectively. The measurements were conducted at $25^{\circ} \mathrm{C}$.

The increased LiTFSI concentration benefits the electrochemical stability of such hybrid electrolytes as can be seen in the linear sweep voltamogramms for 40/20-TFSI and 40/20-OTf compared to $21 \mathrm{~m}$ LiTFSI 
(Fig. 3). The reductive stability was examined using Al electrodes. The oxidative stability was examined using glassy carbon electrodes as they are less redox active in this potential range than, e.g., $\mathrm{Ti}$ or $\mathrm{Au}$ electrodes. ${ }^{28}$ By arbitrarily defining a current density limit of $2 \mu \mathrm{A} \mathrm{cm}{ }^{-2}$, the reductive stability of $40 / 20$ TFSI, 40/20-OTf, and $21 \mathrm{~m} \mathrm{LiTFSI} \mathrm{equals} 0.8,1.3$, and $1.5 \mathrm{~V}$ vs. Li/Li ${ }^{+}$, respectively. Note that on catalytically more active substrates (e.g. stainless steel), lower reductive stability, i.e. higher current densities, can be expected. ${ }^{29}$ Regarding the oxidative stability, 40/20-TFSI also outperforms 40/20-OTf and $21 \mathrm{~m}$ LiTFSI. By considering again a current density limit of $2 \mu \mathrm{A} \mathrm{cm}^{-2}$, the oxidative stability limit of 40/20-TFSI, 40/20OTf, and $21 \mathrm{~m} \mathrm{LiTFSI} \mathrm{is} \mathrm{located} \mathrm{at} 4.7,4.0$, and $4.1 \mathrm{~V}$ vs. $\mathrm{Li}^{\prime} \mathrm{Li}^{+}$, respectively. The lower electrochemical stability observed for 40/20-OTf compared to 40/20-TFSI can be understood by considering that hydrophilic OTf anions interact more strongly with $\mathrm{H}_{2} \mathrm{O}$ than hydrophobic TFSI does, ${ }^{20}$ which weakens the stabilizing $\mathrm{Li}^{+}-\mathrm{H}_{2} \mathrm{O}$ interaction. In addition, molecular dynamics simulations revealed that TFSI but not OTf anions preferentially adsorb at the cathode/electrolyte interphase in WIS electrolytes, forming a water-depletion zone that suppresses the oxygen evolution reaction. ${ }^{9}$

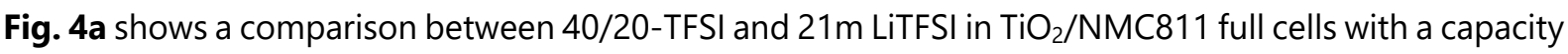
balancing of anode to cathode of $Q_{n}: Q_{p}=1: 1.3$ (considering capacities of 148 and $180 \mathrm{mAh} \mathrm{g}^{-1}$ for $\mathrm{TiO}_{2}$ and NMC811, respectively). The cells were cycled at a rate of $C / 2$ based on the capacity of the negative electrode. The voltage ranges are specified in the figures. All cells were cycled at $25^{\circ} \mathrm{C}$. The enhanced electrochemical stability of 40/20-TFSI clearly translates into much better cycling stability of the cell based on this electrolyte. This cell displays a steady-state Coulombic efficiency (CE) of $>99.7 \%$ and an average CE of $99.65 \%$ during the first 300 cycles compared to a maximum CE of $98 \%$ with $21 \mathrm{~m} \mathrm{LiTFSI.}$ The relatively low CE of the $21 \mathrm{~m}$ LiTFSI cell leads to rapid capacity fading after 50 cycles when the excess $\mathrm{Li}$ ions of the cathode are consumed. In contrast, the $40 / 20$-TFSI cell still retains $80 \%$ of its initial capacity after 290 cycles. This cell displays an initial energy density of $121 \mathrm{Wh} \mathrm{kg}^{-1}$ (based on the weight of the active materials of both electrodes), among the highest energy densities reported for an aqueous Li-ion battery with a $\mathrm{TiO}_{2}$ anode. ${ }^{10}$ The good cycling stability of the 40/20-TFSI cell might be related to suppression of the typical degradation modes of nickel-rich NMC like transition metal dissolution and related surface reconstruction at this very high salt concentration. ${ }^{30}$ Apparently, the $21 \mathrm{~m}$ LiTFSI electrolyte is still not concentrated enough to enable stable cycling of NMC811 as this solution still contains a small fraction of free water molecules. ${ }^{6}$

Importantly, the high reductive stability of the 40/20-TFSI electrolyte also allows stable cycling of niobiacoated LTO anodes (see experimental section for details). Fig. $\mathbf{4 b}$ shows cycling data for a LTO/NMC811 cell. For easy comparison with the $\mathrm{TiO}_{2} / \mathrm{NMC} 811$ cell, balancing and cycling conditions were kept the same. For the balancing of the cell, we considered a capacity of 160 and $180 \mathrm{mAh} \mathrm{g}^{-1}$ for LTO and NMC811, respectively. The more challenging, i.e. more negative, redox potential of LTO results in a lower CE of $99.2 \%$, which also translates into faster capacity decay. However, the energy density of the cell benefits from the higher cell voltage, resulting in a very high initial energy density for an aqueous intercalation type Li-ion battery of $150 \mathrm{Wh} \mathrm{kg}^{-1}$. Increasing the $\mathrm{C}$-rate to $1 \mathrm{C}$ and supplying a larger excess of cathode capacity $\left(Q_{n}: Q_{p}=1: 1.5\right)$ to better compensate the lower CE compared to the $\mathrm{TiO}_{2} / \mathrm{NMC} 811$ cell leads to much improved cell performance as shown in Fig. 4c. 
a)

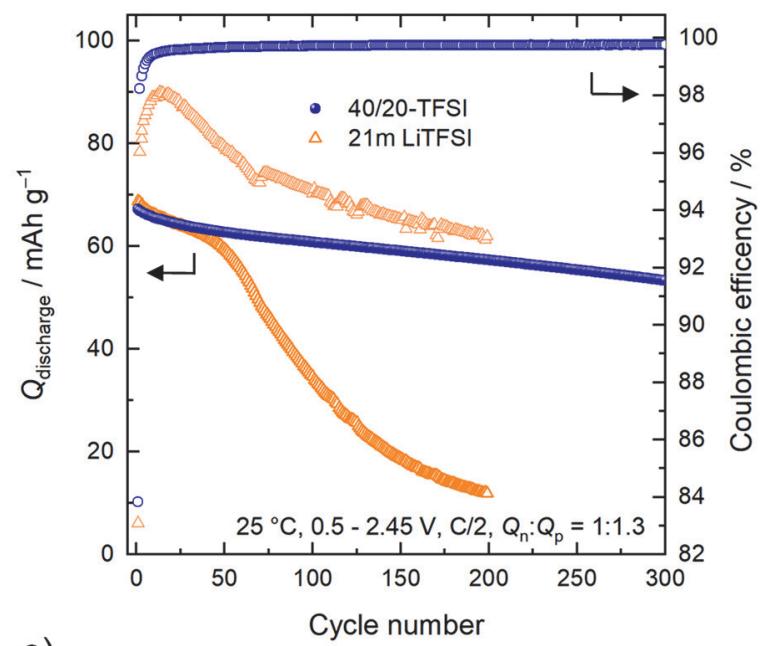

b)

LTO vs. NMC811

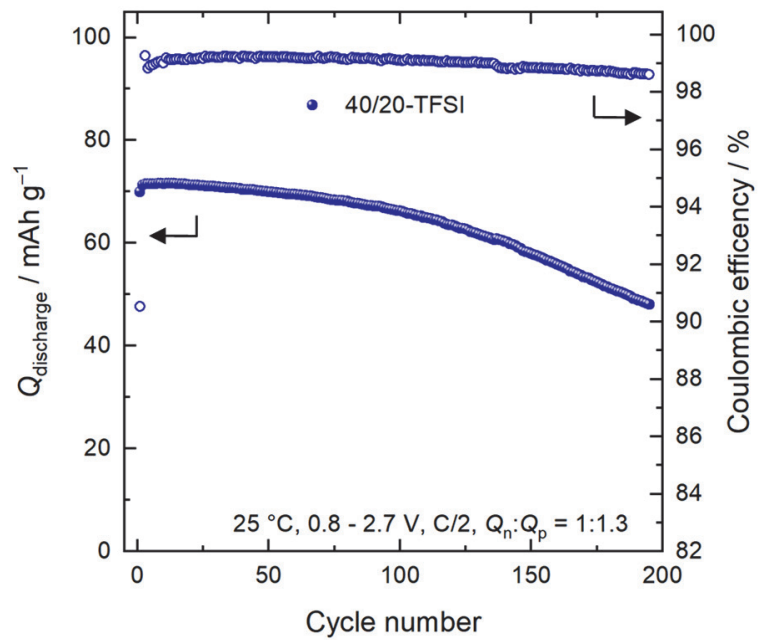

c)

LTO vs. NMC811

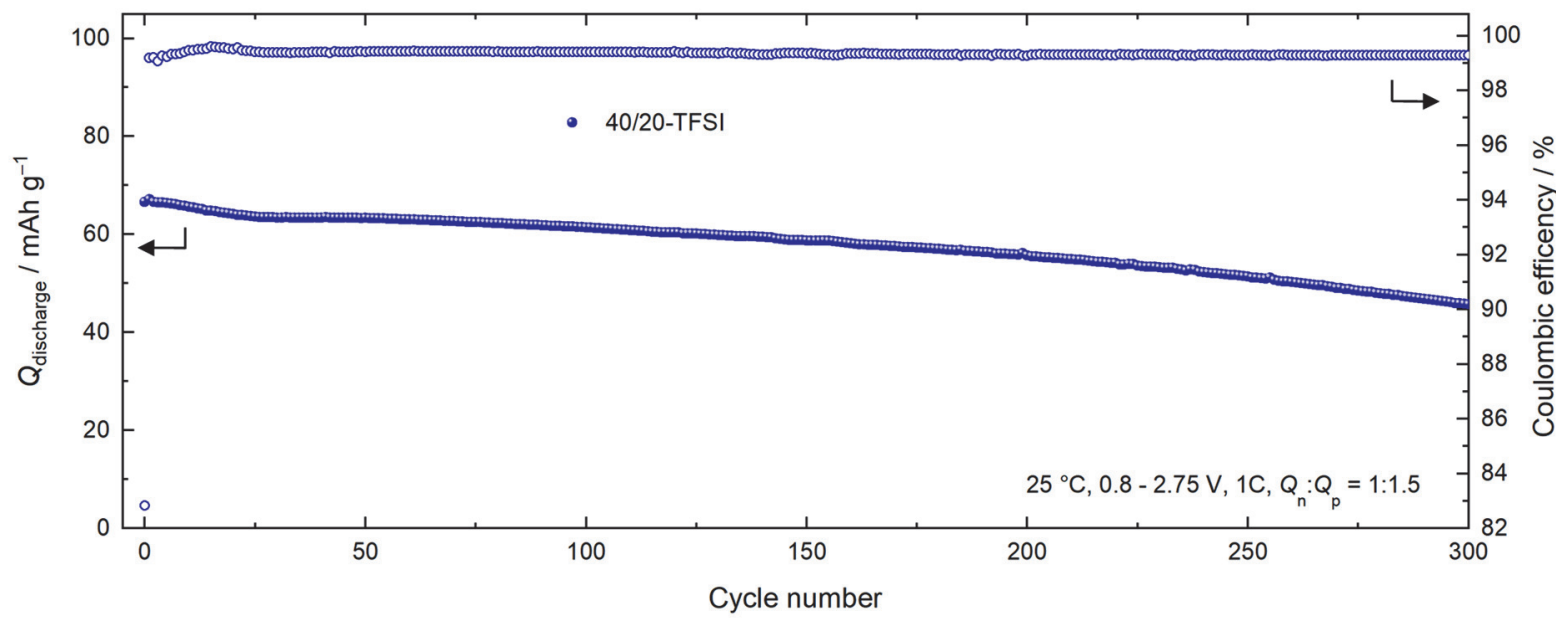

Fig. 4: Cycling performance of various full cells containing 40/20-TFSI as the electrolyte. (a) $\mathrm{TiO}_{2} / \mathrm{NMC} 11$ full cell cycled at $\mathrm{C} / 2$. For comparison, data for a cell containing $21 \mathrm{~m} \mathrm{LiTFSI}$ as the electrolyte is also shown. $m\left(\mathrm{TiO}_{2}\right)=1.7$ mg. (b) LTO/NMC811 full cell cycled at C/2. $m($ LTO $=3.2 \mathrm{mg}$. (c) LTO/NMC811 full cell cycled at $1 \mathrm{C}$. $m(\mathrm{LTO})=1.8 \mathrm{mg}$. The applied current was based on the weight of the anode active material for all cells.

This cell cycles with a CE of $99.4 \%$ and retains $80 \%$ of its initial capacity after 230 cycles. The enhanced cycling stability comes at the price of a slightly lower initial energy density of $141 \mathrm{Wh} \mathrm{kg}^{-1}$.

To further test the oxidative stability of the 40/20-TFSI electrolyte and its compatibility with LMO, we assembled an LTO/LMO full cell with a $Q_{n}: Q_{p}$ ratio of $1: 1.3$ (considering a capacity of $120 \mathrm{mAh} \mathrm{g}^{-1}$ for LMO) and cycled the cell at $1 \mathrm{C}$ (Fig. 5a). The cell displays an average CE of $99.4 \%$ during the first 300 cycles and retains $80 \%$ of its initial capacity after 186 cycles. Due to the lower specific capacity of LMO, the cell has a lower capacity of $59 \mathrm{mAh} \mathrm{g}^{-1}$ (based on the active mass of both electrodes) compared to $67 \mathrm{mAh} \mathrm{g}^{-1}$ for the LTO/NMC811 cell shown in Fig. 4c. However, the higher redox potential of LMO partially compensates for its lower capacity compared to NMC811, still translating to an energy density of $137 \mathrm{Wh} \mathrm{kg}^{-1}$. The difference in capacity and voltage characteristics of these two cells is illustrated with the voltage profiles of the first cycles shown in Fig. $\mathbf{5 b}$. 
a)

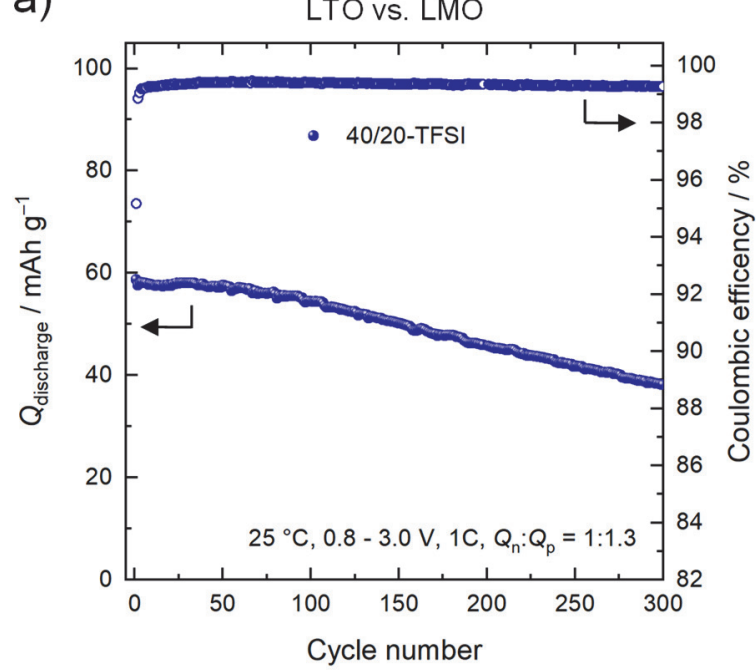

b)

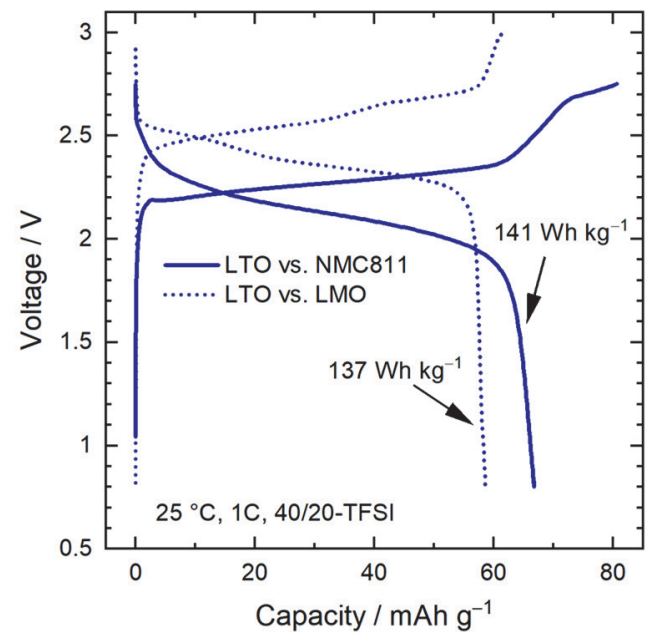

Fig. 5: (a) LTO/LMO full cell cycled at 1C. 40/20-TFSI was used as the electrolyte. $m($ LTO $)=2.5 \mathrm{mg}$. The applied current was based on the weight of the anode active material. (b) Voltage profiles of the $1^{\text {st }}$ cycle of the LTO/NMC811 and LTO/LMO full cells cycled at $1 \mathrm{C}$ shown in Fig. $4 \mathrm{c}$ and Fig. $5 \mathrm{a}$, respectively.

\section{Conclusions}

Increasing the lithium salt concentration is an effective strategy to widen the stability window of waterin-salt electrolytes and to tackle the cathodic challenge. However, when increasing the concentration beyond $30 \mathrm{~mol} \mathrm{~kg}^{-1}$, the gain in stability is increasingly overcompensated by a reduction in transport properties. Binary lithium salt-ionic liquid electrolytes offer higher electrochemical stability than waterin-salt electrolytes but suffer from high viscosities and particularly from low lithium-ion conductivities, even at high lithium molar fractions, that limit their practical use to high temperatures. ${ }^{31,32}$ Ternary lithium salt-ionic liquid-water mixtures provide a better compromise between stability and conductivity compared to binary lithium salt-water and lithium salt-ionic liquid electrolytes. For the LiTFSIEMImTFSI/EMImOTf-water electrolytes studied here, we observed a two-fold benefit of adding these ionic liquids to water-in-salt electrolytes: On the one hand, the bulky ions of these ionic liquids act as a kind of plasticizer, lowering the viscosity of highly concentrated LiTFSI-water solutions. On the other hand, the presence of these ionic liquids boosts the LiTFSI solubility. In the case of EMImOTf, the LiTFSI solubility increases to up to $60 \mathrm{~mol} \mathrm{~kg}^{-1}$ with respect to water. These extremely high values cannot be explained by the sum of the LiTFSI solubilities in water and in the ionic liquid itself. When deconvoluting the different contributions to the LiTFSI solubility, we found large excess solubilities. Future studies should focus on the interplay between water, lithium salt, and ionic liquid to elucidate the solubilityenhancing effect of these ionic liquids.

We found that EMImTFSI-based electrolytes display higher electrochemical stability then EMImOTfbased ones. Furthermore, when limiting the LiTFSI and EMImTFSI concentrations to 40 and $20 \mathrm{~mol} \mathrm{~kg}^{-1}$, respectively, the electrolyte still shows an acceptable ionic conductivity of $1.2 \mathrm{mS} \mathrm{cm}^{-1}$ at $25^{\circ} \mathrm{C}$. The high LiTFSI concentration of this electrolyte translates into improved reductive stability as demonstrated by good compatibility with $\mathrm{TiO}_{2}$ and niobia-coated LTO anodes. In addition, the reduced water content also allows stable cycling of NMC811 cathodes. Paired with a $\mathrm{TiO}_{2}$ anode, a $\mathrm{TiO}_{2} / \mathrm{NMC} 811$ full cell based on this electrolyte displays a Coulombic efficiency of $>99.7 \%$ at $\mathrm{C} / 2$ and consequently good cycling stability 
for $>300$ cycles compared to an efficiency of $<98 \%$ and rapid capacity fading when using $21 \mathrm{~m} \mathrm{LiTFSI}$ as the electrolyte. For LTO/NMC811 full cells, we obtain Coulombic efficiencies of $99.2 \%$ and $99.4 \%$ at rates of $1 \mathrm{C}$ and C/2, respectively. Due to the high capacity of NMC811, LTO/NMC811 full cells incorporating the hybrid electrolyte also display very high energy density for aqueous intercalation-type batteries of up to $150 \mathrm{Wh} \mathrm{kg}^{-1}$ on the active material level.

Further improvements of such ternary electrolytes and subsequently cell performance can be expected considering the large number of potential lithium salt-ionic liquid combinations. This approach might also invigorate the development of aqueous batteries based on other cell chemistries such as sodiumion that have suffered from low salt solubilities. 


\section{Experimental Section}

\section{Electrolyte preparation and physicochemical characterization}

LiTFSI (99.9\%, Solvionic), EMImTFSI (99.9\%, Solvionic), and EMImOTf (99.5\%, Solvionic) were used as received and stored under an inert argon atmosphere in a glovebox (MBraun). The electrolytes were prepared by dissolving the respective amount of LiTFSI and/or RTIL in high-purity water (deionized water further purified with a Millipore Milli-Q water purification system). After preparation, the electrolytes showed a $\mathrm{pH}$ value between 6 and 7. $\mathrm{pH}$ values were determined using $\mathrm{pH}$ paper (Merck) with a $\mathrm{pH}$ range from 1 to 14 . Before use, electrolytes were thoroughly degassed with Ar and stored under an inert argon atmosphere in a glovebox (MBraun).

Differential scanning calorimetry was carried out with a Netzsch STA 449 F3 simultaneous thermal analyzer. Ca. $30 \mathrm{mg}$ of electrolyte sample were mixed with ca. $1 \mathrm{mg}$ of mesocarbon microbeads as crystallization agent and hermetically sealed in Al pans. All measurements were carried out at a scan rate of $1^{\circ} \mathrm{C} \mathrm{min}-1$. The samples were equilibrated at $60{ }^{\circ} \mathrm{C}$ for 30 min prior to the start of the measurement. Ionic conductivity was determined via impedance spectroscopy (Bio-Logic MCS 10) in sealed 2-electrode cells equipped with Pt electrodes (Bio-Logic HTCC). Viscosity was determined with a Kyoto Electronics Manufacturing EMS-1000 electromagnetically spinning viscometer using $2 \mathrm{~mm}$ Al spheres. Sample volumes of $400 \mu \mathrm{L}$ were used. Samples were equilibrated for $15 \mathrm{~min}$ at each temperature.

Electrochemical stability was determined via linear sweep voltammetry in 3-electrode configuration with a Bio-Logic VMP3 electrochemical workstation at $25^{\circ} \mathrm{C}$. Cathodic scans were carried out using a Swagelok T-cell with Al foil discs ( $d=12 \mathrm{~mm}, \mathrm{MTI}$, >99.3\%) as working electrode, activated carbon pellets as counter electrode, and a miniature $\mathrm{Ag} / \mathrm{AgCl}$ electrode (eDAQ) was used as reference electrode. Anodic scans were carried out in small volume glass cells (eDAQ) with a glassy carbon working electrode ( $d=1 \mathrm{~mm}$, eDAQ, type ET074), a Pt-coated Ti rod (eDAQ) as counter electrode, and a miniature $\mathrm{Ag} / \mathrm{AgCl}$ electrode (eDAQ) as reference electrode. The scan rate was set to $1 \mathrm{mV} \mathrm{s}^{-1}$.

\section{Electrode fabrication and battery assembly}

$\mathrm{TiO}_{2}$ (Sigma Aldrich, anatase, < $25 \mathrm{~nm}, 99.7 \%$ ) was coated with a carbon layer by dispersing the pristine powder in D-(+)-glucose dissolved in ethanol with a Ti:C ratio of 2:1. After solvent evaporation, the remaining powder was calcined in a tube furnace under $\mathrm{Ar}$ atmosphere at $600^{\circ} \mathrm{C}$ for $2 \mathrm{~h}$ with the heating rate set to $4 \mathrm{~K} \mathrm{~min}^{-1}$.

Carbon-coated $\mathrm{TiO}_{2}$, LTO (Targray, type LTO-2s, 4-10 $\mu \mathrm{m}$ (D50), $\leq 8 \mathrm{~m}^{2} \mathrm{~g}^{-1}$ ), and LMO (Targray, type SLMO03001, $17.5 \mu \mathrm{m}$ (D50), 0.2-0.7 $\mathrm{m}^{2} \mathrm{~g}^{-1}$ ) electrodes were prepared by dispersing the active material with PVdF binder (Arkema Kynar HSV900) and carbon black (IMERYS Graphite \& Carbon C-NERGY SUPER C65) in a mass ratio of 8:1:1 in N-methyl-2-pyrrolidone. NMC811 (Targray, type SNMC03001, $6.5 \mu \mathrm{m}$ (D50), $0.5 \mathrm{~m}^{2} \mathrm{~g}^{-1}$ ) electrodes were prepared with a mass ratio of 94:3:3 using the same binder and conductive additive. The slurry was tape casted using a doctor blade onto Al foil $\left(\mathrm{TiO}_{2}, \mathrm{LTO}\right)$ or Ti foil (LMO, NMC811). The electrodes were first dried for at least $2 \mathrm{~h}$ at $120^{\circ} \mathrm{C}$ in air and subsequently dried at $120{ }^{\circ} \mathrm{C}$ over night under oil pump vacuum. Except for LTO, all electrodes were pressed at $1 \mathrm{t} \mathrm{cm}^{-2}$ for $30 \mathrm{~s}$ after punching out electrode discs with a diameter of $12 \mathrm{~mm}$. 
LTO electrode sheets were coated with a niobium oxide layer by atomic layer deposition (ALD) at a substrate temperature of $175^{\circ} \mathrm{C}$ with argon as carrier gas at a base pressure of $19 \mathrm{~Pa}$ in a Fiji G2 system (Veeco Instruments). The precursors were niobium( $(\mathrm{V})$ ethoxide $\left(\mathrm{Nb}(\mathrm{OEt})_{5}\right)$ (Sigma Aldrich) and $\mathrm{H}_{2} \mathrm{O}$. $\mathrm{Nb}(\mathrm{OEt})_{5}$ was kept at $160{ }^{\circ} \mathrm{C}$ while $\mathrm{H}_{2} \mathrm{O}$ was unheated. The growth rate was determined by ellipsometry on Si (100) reference substrates, and linear growth was observed with a growth rate of $0.42 \AA$ cycle ${ }^{-1}$.

Two-electrode full cells were assembled using CR2032 coin cells (stainless steel) with an Al-coated negative cell casing part and a $16 \mathrm{~mm}$ Ti disc between positive electrode and spacer disc $(1 \mathrm{~mm})$. Whatman GF/D glass microfiber filters with a diameter of $15 \mathrm{~mm}$ were used as separators. The electrolyte volume was set to $100 \mu \mathrm{L}$. All cells were assembled under inert atmosphere in an argon-filled glovebox (MBraun). All cycling data was obtained at $25^{\circ} \mathrm{C}$.

\section{References}

(1) Xu, K. Electrolytes and Interphases in Li-Ion Batteries and Beyond. Chem. Rev. 2014, 114, 1150311618.

(2) Dougherty, D. H.; Roth, E. P. A General Discussion of Li lon Battery Safety. Electrochem. Soc. Interface 2012, 21, 37-44.

(3) Appetecchi, G. B.; Montanino, M.; Passerini, S. Ionic Liquid-Based Electrolytes for High Energy, Safer Lithium Batteries. ACS Symp. Ser. 2012, 1117, 67-128.

(4) Wang, J.; Yamada, Y.; Sodeyama, K.; Chiang, C. H.; Tateyama, Y.; Yamada, A. Superconcentrated Electrolytes for a High-Voltage Lithium-Ion Battery. Nat. Commun. 2016, 7, 12032.

(5) Chawla, N.; Bharti, N.; Singh, S. Recent Advances in Non-Flammable Electrolytes for Safer LithiumIon Batteries. Batteries 2019, 5, 19-34.

(6) Suo, L.; Borodin, O.; Gao, T.; Olguin, M.; Ho, J.; Fan, X.; Luo, C.; Wang, C.; Xu, K. "Water-in-Salt" Electrolyte Enables High-Voltage Aqueous Lithium-Ion Chemistries. Science 2015, 350, 938-943.

(7) Suo, L.; Oh, D.; Lin, Y.; Zhuo, Z.; Borodin, O.; Gao, T.; Wang, F.; Xu, K.; Wang, C. How SolidElectrolyte Interphase Forms in Aqueous Electrolytes. J. Am. Chem. Soc. 2017, 139, 18670-18680.

(8) Dubouis, N.; Lemaire, P.; Mirvaux, B.; Salager, E.; Deschamps, M.; Grimaud, A. The Role of the Hydrogen Evolution Reaction in the Solid - Electrolyte Interphase Formation Mechanism. Energy Environ. Sci. 2018, 11, 3491-3499.

(9) Vatamanu, J.; Borodin, O. Ramifications of Water-in-Salt Interfacial Structure at Charged Electrodes for Electrolyte Electrochemical Stability. J. Phys. Chem. Lett. 2017, 8, 4362-4367.

(10) Suo, L.; Borodin, O.; Sun, W.; Fan, X.; Yang, C.; Wang, F.; Gao, T.; Ma, Z.; Schroeder, M.; von Cresce, A.; et al. Advanced High-Voltage Aqueous Lithium-Ion Battery Enabled by "Water-in-Bisalt" Electrolyte. Angew. Chemie Int. Ed. 2016, 55, 7136-7141.

(11) Yamada, Y.; Usui, K.; Sodeyama, K.; Ko, S.; Tateyama, Y.; Yamada, A. Hydrate-Melt Electrolytes for High-Energy-Density Aqueous Batteries. Nat. Energy 2016, 1, 16129.

(12) Reber, D.; Kühnel, R.-S.; Battaglia, C. Suppressing Crystallization of Water-in-Salt Electrolytes by Asymmetric Anions Enables Low-Temperature Operation of High-Voltage Aqueous Batteries. ACS Mater. Lett. 2019, 1, 44-51.

(13) Becker, M.; Kühnel, R.-S.; Battaglia, C. Water-in-Salt Electrolytes for Aqueous Lithium-Ion Batteries with Liquidus Temperatures below $-10^{\circ} \mathrm{C}$. Chem. Commun. 2019, 55, 12032-12035.

(14) Ko, S.; Yamada, Y.; Miyazaki, K.; Shimada, T.; Watanabe, E.; Tateyama, Y.; Kamiya, T.; Honda, T.; Akikusa, J.; Yamada, A. Lithium-Salt Monohydrate Melt: A Stable Electrolyte for Aqueous LithiumIon Batteries. Electrochem. Commun. 2019, 104, 106488.

(15) Chen, J.; Vatamanu, J.; Xing, L.; Borodin, O.; Chen, H.; Guan, X.; Liu, X.; Xu, K.; Li, W. Improving 
Electrochemical Stability and Low-Temperature Performance with Water/Acetonitrile Hybrid Electrolytes. Adv. Energy Mater. 2020, 10, 1902654.

(16) Jiang, L.; Liu, L.; Yue, J.; Zhang, Q.; Zhou, A.; Borodin, O.; Suo, L.; Li, H.; Chen, L.; Xu, K.; et al. HighVoltage Aqueous Na-lon Battery Enabled by Inert-Cation-Assisted Water-in-Salt Electrolyte. Adv. Mater. 2020, 32, 1904427.

(17) Chen, L.; Zhang, J.; Li, Q.; Vatamanu, J.; Ji, X.; Pollard, T. P.; Cui, C.; Hou, S.; Chen, J.; Yang, C.; et al. A 63 m Superconcentrated Aqueous Electrolyte for High-Energy Li-Ion Batteries. ACS Energy Lett. 2020, 5, 968-974.

(18) Sakaebe, H.; Matsumoto, H. N-Methyl-N-propylpiperidinium Bis(trifluoromethanesulfonyl)imide (PP13-TFSI) - Novel Electrolyte Base for Li Battery. Electrochem. Commun. 2003, 5, 594-598.

(19) Tsuzuki, S.; Tokuda, H.; Hayamizu, K.; Watanabe, M. Magnitude and Directionality of Interaction in Ion Pairs of Ionic Liquids: Relationship with Ionic Conductivity. J. Phys. Chem. B 2005, 109, 16474-16481.

(20) Jankowski, P.; Wieczorek, W.; Johansson, P. Functional Ionic Liquids: Cationic SEI-Formers for Lithium Batteries. Energy Storage Mater. 2019, 20, 108-117.

(21) Osada, I.; de Vries, H.; Scrosati, B.; Passerini, S. Ionic-Liquid-Based Polymer Electrolytes for Battery Applications. Angew. Chemie Int. Ed. 2016, 55, 500-513.

(22) Kobayashi, K.; Pagot, G.; Vezzù, K.; Bertasi, F.; Di Noto, V.; Tominaga, Y. Effect of Plasticizer on the Ion-Conductive and Dielectric Behavior of Poly(Ethylene Carbonate)-Based Li Electrolytes. Polym. J. 2020. https://doi.org/10.1038/s41428-020-00397-4.

(23) Seki, S.; Ohno, Y.; Kobayashi, Y.; Miyashiro, H.; Usami, A.; Mita, Y.; Tokuda, H.; Watanabe, M.; Hayamizu, K.; Tsuzuki, S.; et al. Imidazolium-Based Room-Temperature lonic Liquid for Lithium Secondary Batteries. J. Electrochem. Soc. 2007, 154, A173-A177.

(24) Tsuzuki, S.; Hayamizu, K.; Seki, S. Origin of the Low-Viscosity of [emim][( $\left.\left.\mathrm{FSO}_{2}\right)_{2} \mathrm{~N}\right]$ lonic Liquid and Its Lithium Salt Mixture: Experimental and Theoretical Study of Self-Diffusion Coefficients, Conductivities, and Intermolecular Interactions. J. Phys. Chem. B 2010, 114, 16329-16336.

(25) Li, Z.; Smith, G. D.; Bedrov, D. Li+ Solvation and Transport Properties in lonic Liquid/Lithium Salt Mixtures: A Molecular Dynamics Simulation Study. J. Phys. Chem. B 2012, 116, 12801-12809.

(26) Asenbauer, J.; Ben Hassen, N.; McCloskey, B. D.; Prausnitz, J. M. Solubilities and lonic Conductivities of Ionic Liquids Containing Lithium Salts. Electrochim. Acta 2017, 247, 1038-1043.

(27) Ding, M. S.; Xu, K. Phase Diagram, Conductivity, and Glass Transition of LiTFSI- $\mathrm{H}_{2} \mathrm{O}$ Binary Electrolytes. J. Phys. Chem. C 2018, 122, 16624-16629.

(28) Coustan, L.; Shul, G.; Bélanger, D. Electrochemical Behavior of Platinum , Gold and Glassy Carbon Electrodes in Water-in-Salt Electrolyte. Electrochem. Commun. 2017, 77, 89-92.

(29) Kühnel, R.-S.; Reber, D.; Battaglia, C. Perspective-Electrochemical Stability of Water-in-Salt Electrolytes. J. Electrochem. Soc. 2020, 167, 070544.

(30) Li, T.; Yuan, X.-Z.; Zhang, L.; Song, D.; Shi, K.; Bock, C. Degradation Mechanisms and Mitigation Strategies of Nickel-Rich NMC-Based Lithium-Ion Batteries. Electrochem. Energy Rev. 2020, 3, 4380.

(31) Molinari, N.; Mailoa, J. P.; Kozinsky, B. General Trend of a Negative Li Effective Charge in lonic Liquid Electrolytes. J. Phys. Chem. Lett. 2019, 10, 2313-2319.

(32) Frömling, T.; Kunze, M.; Schönhoff, M.; Sundermeyer, J.; Roling, B. Enhanced Lithium Transference Numbers in Ionic Liquid Electrolytes. J. Phys. Chem. B 2008, 112, 12985-12990. 